\title{
Media Pembelajaran Interaktif Matematika Berbasis Flash Pada Siswa Kelas 1 MI NW Liqaul Amal
}

\author{
Yupi Kuspandi Putra1 ${ }^{1}$ Muhamad Sadali2 ${ }^{2}$ Irwan Hadi ${ }^{3}$ \\ 1,3Program Studi Sistem Informasi, Universitas Hamzanwadi \\ 2Program Studi Teknik Informatika, Universitas Hamzanwadi \\ *yupi.putra@gmail.com
}

\begin{abstract}
Abstrak
Tujuan penelitian ini adalah untuk mempermudah dalam kegiatan belajar mengajar, sehingga dapat meningkatkan pemahaman siswa terhadap materi matematika yang disampaikan oleh guru serta dapat dijadikan sebagai media untuk meningkatkan minat dan ketertarikan dalam proses belajar. Media pembelajaran berperan penting dalam kegiatan belajar mengajar supaya proses belajar mengajar menjadi efektif dan mudah diterapkan, namun kenyataan dalam dunia pendidikan media pembelajaran sering tidak diperhatikan dengan alasan terbatasnya waktu untuk membuat persiapan mengajar dan sulit mencari media yang tepat. Di MI NW Liqaul Amal masih menggunakan media pembelajaran yang masih manual menggunakan media buku, tulisan dan alat peraga lainnya sebagai alat belajar siswa, media pembelajaran seperti ini masih belum dapat meningkatkan minat siswa terutama dalam pelajaran matematika. Salah satu metode pembelajaran yang digunakan untuk mengatasi permasalahan tersebut adalah dengan membuat media pembelajaran interaktif pada mata pelajaran matematika. Media pembelajaran ini dimulai dari proses analisis kebutuhan yang akan digunakan dalam pembuatan media pembelajaran interaktif berbasis flash dan membuat konsep atau perancangan sesuai dengan hasil analisis. Hasil yang akan dicapai dalam pembuatan media pembelajaran interaktif pada mata pelajaran matematika ini adalah bahwa siswa dapat memahami materi dan meningkatkan minat belajar siswa, sehingga proses belajar mengajar menjadi lebih efektif.
\end{abstract}

Kata kunci : Media pembelajaran, Media interaktif, Adobe Flash

\begin{abstract}
The purpose of this study is to facilitate teaching and learning activities, so that it can improve students' understanding of the mathematics material presented by the teacher and can be used as a medium to increase interest and interest in the learning process. Learning media plays an important role in teaching and learning activities so that the teaching and learning process becomes effective and easy to apply, but in reality in the world of education learning media is often not paid attention to because of limited time to make teaching preparation and it is difficult to find the right media. At MI NW Liqaul Amal still using manual learning media using books, writing and other teaching aids as student learning tools, learning media like this still cannot increase student interest, especially in mathematics lessons. One of the learning methods used to overcome these problems is to create interactive learning media in mathematics subjects. This learning media starts with a needs analysis process that will be used in making flash-based interactive learning media and making concepts or designs according to the results of the analysis. The results to be achieved in making interactive learning media on mathematics subjects are that students can understand the material and increase student interest in learning, so that the teaching and learning process becomes more effective.
\end{abstract}

Keywords: Learning media, Interactive media, Adobe Flash 


\section{Pendahuluan}

Penggunaan teknologi yang semakin pesat telah merambah ke semua lini kehidupan, baik itu sektor ekonomi, kesehatan, pendidikan, dan lainlain. Pada bidang pendidikan misalnya pemanfaatan teknologi bisa kita lihat dengan banyaknya media belajar online yang sudah ada saat ini seperti ruang guru, zenius, dan lain- lain. Pemanfaatan teknologi dalam pendidikan yang lainnya bisa kita lihat dari UN yang sudah dari beberapa tahun lalu sudah menggunakan sistem online. Dari berkembangnya teknologi dan pemanfaatannya di bidang pendidikan mau tidak mau sekolah-sekolah harus bisa memanfaatkan teknologi untuk mendukung sistem belajar mengajar agar lebih efisien serta untuk memenuhi kebutuhan siswa yang saat ini sudah tidak asing lagi dengan yang namanya teknologi. MI NW Liqaul Amal merupakan madrasah ibtidaiyah yang berada di dusun Liqaul Amal Desa Sepit Kecamatan Keruak. Dimana madrasah ini berdiri sejak tahun 2000 dan mulai beroperasi sejak tahun 2002. Proses belajar mengajar di madrasah ibtidaiyah ini masih terbilang manual dengan menggunakan media buku paket sebagai media utamanya. Dimana proses belajar mengajar yang demikian itu terkadang membuat siswa jenuh dalam belajar. Berdasarkan masalah tersebut dibutuhkan media pembelajaran interaktif dalam proses belajar mengajar yang nantinya bisa menjadi alternatif belajar mengajar yang dapat diterapkan pada MI NW Liqaul Amal. Sehingga siswa dapat memahami materi dan meningkatkan minat belajar siswa, serta proses belajar mengajar menjadi lebih efektif.

\section{Tinjauan Pustaka}

\subsection{Penelitian Terkait}

Ada beberapa penelitian yang sudah dilakukan sebelumnya yang terkait dengan penelitian ini antara lain :

Penelitian yang dilakukan oleh Bahtiar H. dkk, menyimpulkan bahwa dengan adanya digitalisasi Karya TGKH. Muhammad Zainuddin Abdul Madjid berbasis mobile sebagai media pembelajaran interaktif untuk pelestarian peninggalan pendiri Nahdlatul Wathan menjadi salah satu soluai akan membantu murid-murid beliau yang notabennya tidak memiliki kitab tersebut dan terhalang dengan jarak dan waktu. Pengerjaan dimulai dengan pengetikan isi kitab yang dilanjutkan dengan implementasi aplikasi, dan pada akhirnya aplikasi bisa dimanfaatkan lebih lanjut [1]. Kemudian penelitian yang dilakukan oleh Sudianto, A., \& Samsu, L. M. bahwasanya media pembelajaran interaktif lebih efektif dari metode pembelajaran ceramah. Karena metode ceramah hanya membuat siswa lebih menjadi pasif dan apabila menerapkan media pembelajaran interaktif lebih memancing respon siswa terhadap suatu pelajaran [2]. 
Menurut Wirasasmita, R. H., \& Putra, Yupi K. dalam penelitiannya berjudul Pengembangan Media Pembelajaran Video Tutorial Interaktif Menggunakan Aplikasi Camtasia Studio Dan Macromedia Flash, menyatakan bahwa Media pembelajaran berbasis video $C D$ tutorial interaktif ini dapat menjadi suplemen bagi mahasiswa walaupun sifatnya hanya pilihan tapi dapat dimanfaatkan juga untuk menambah pengetahuan, wawasan khususnya tentang matakuliah bahasa pemrograman visual materi bahasa pemrograman delphi serta memudahkan proses belajar mengajar serta meningkatkan kualitas pembelajaran dan prestasi belajar mahasiswa [3]. Sedangkan menurut Hariman Bahtiar dalam jurnal yang berjudul "Sistem Informasi Wisata dan Budaya Pulau Lombok dengan Multimedia Intraktif Untuk Meningkatkan Kunjungan Wisata" di dapatkan kesimpulan sebagai berikut: Sistem informasi berbasis multimedia dapat meningkatkan efektifitas informasi. Perancangan yang matang dan hatihati menjadi sarat mutlak keberhasilan pemanfaatan teknologi multimedia. Dalam dunia informasi, penggunaan multimedia lebih digunakan karena multimedia dapat menghilangkan kejenuhan dengan memanfaatkan tampilan visualisasi yang dapat dinikmati dan mampu memberikan kesan hidup dengan animasi [4]. Begitu juga dengan Fathurrahman dkk, dalam penelitiannya menyatakan bahwa dengan media pembelajaran interaktif dapat memotivasi dan meningkatkan minat belajar siswa ${ }^{[5]}$.

\subsection{Landasan Teori}

1. Multimedia

Secara harfiah, kata "multimedia" terdiri dari kata 'multi' yang berarti banyak dan 'media' yang berarti alat atau sarana untuk menyampaikan informasi sehingga multimedia dapat dikaitkan dengan elemen media yang digabungkan. Dengan demikian, pengertian multimedia adalah penyajian dari suatu aplikasi komputer, biasanya interaktif, yang menggabungkan elemen media seperti teks, grafik, video, animasi, dan suara pada komputer. Definisi multimedia beragam tergantung pada lingkup aplikasi serta perkembangan teknologi multimedia itu sendiri. Multimedia tidak hanya memiliki makna antara teks dan grafik sederhana saja, tetapi juga dilengkapi dengan suara, animasi, video, dan interaksi. Sambil mendengarkan penjelasan dapat melihat gambar, animasi maupun membaca penjelasan dalam bentuk teks. Multimedia mengkombinasi teks, seni, suara, gambar, animasi, dan video yang disampaikan secara interaktif [6]. Berbagai sumber tentang pengertian multimedia yang menyebutkan bahwa multimedia adalah kumpulan dari berbagai elemen media seperti teks, grafik, gambar, video, animasi, audio dan interaktif yang tersaji ke 
dalam satu media dan memiliki fungsi saling mendukung antara satu dengan yang lainnya sehingga dapat memberikan pengaruh dan rangsangan terhadap tujuan pembelajaran [7].

\section{Media}

Kata media berasal dari bahasa latin medium yang secara harafiah berarti tengah, perantara atau pengantar. Secara khusus pengertian media dalam proses belajar mengajar lebih cenderung diartikan sebagai alat tulis grafis, fotografis, atau elektronik untuk menangkap, memproses, dan menyusun kembali informasi visual atau verbal ${ }^{[8]}$.

\section{Media interaktif}

Multimedia interaktif adalah suatu multimedia yang dilengkapi dengan alat pengontrol yang dapat dioperasikan oleh pengguna, sehingga pengguna dapat memilihapa yang dikehendaki untuk proses selanjutnya. Contoh multimedia interaktif adalah pembelajaran interaktif, aplikasi game [12]. Bentukbentuk dalam pemanfaatan model dalam media pembelajaran interaktif berbasis komputer maupun android dalam media pembelajaran terdapat berupa drill, tutorial, simulation, dan games. Pada dasarnya salah satu tujuan pembelajaran dengan multimedia interaktif adalah sedapat mungkin menggantikan dan atau melengkapi serta mendukung unsur-unsur seperti tujuan, materi, metode, dan alat penilaian yang ada dalam proses belajar mengajar dalam sistem pendidikan konvensional yang biasa kita lakukan [2].
4. Media Pembelajaran

Media pembelajaran adalah alat atau sarana yang digunakan untuk melaksanakan proses belajar mengajar. Baik berupa alat elektronik atau alat peraga, media pembelajaran interaktif adalah proses belajar mengajar yang menggunakan media atau sarana yang bisa saling berkomunikasi atau saling merespon [11].

Tujuan penggunaan media belajar dalam proses belajar mengajar bukan sekedar untuk melengkapi proses belajar mengajar dan untuk menarik perhatian peserta didik saja, akan tetapi penggunaan media dalam proses belajar mengajar itu bertujuan untuk memfasilitasi dan mempermudah proses belajar mengajar sehingga dapat meningkatkan kualitas belajar mengajar dan tercapainya tujuan belajar [9]. Menurut [10], mengemukakan manfaat media pengajaran dalam proses belajar siswa yaitu : Pengajaran akan lebih menarik perhatian siswa sehingga dapat menumbuhkan motivasi belajar. Bahan pengajaran akan lebih jelas maknanya sehingga dapat lebih dipahami oleh siswa dan memungkinkannya menguasai dan mencapai tujuan pengajaran.

Kontribusi media pembelajaran dapat menjadikan pembelajaran lebih menarik, kualitas pembelajaran dapat ditingkatkan, sifat positif komunikasi terhadap materi pembelajaran dan peran komunikator mengalami perubahan kearah yang positif. Berdasarkan pemaparan tersebut 
maka dapat diambil kesimpulan bahwa media pembelajaran merupakan bentuk materi sebagai sarana perantara dalam proses belajar mengajar untuk mencapai suatu tujuan pembelajaran yang memiliki manfaat yaitu dapat memperjelas pesan agar tidak terlalu verbalitas, mengatasi keterbatasan, memberi rangsangan yang dapat menyamakan pemahaman komunikasi peserta dapat memberikan pembelajaran yang efektif dan efisien [13].

\section{Adobe Flash}

Sebelum tahun 2005, Flash dirilis oleh Macromedia. Flash 1.0 diluncurkan pada tahun 1996 setelah Macromedia membeli program animasi vektor bernama FutureSplash. Versi terakhir yang diluncurkan di pasaran dengan menggunakan nama 'Macromedia' adalah Macromedia Flash 8. Pada tanggal 3 Desember 2005 Adobe Systems mengakuisisi Macromedia dan seluruh produknya, sehingga nama Macromedia Flash berubah menjadi Adobe Flash.

Adobe Flash merupakan sebuah program yang didesain khusus oleh Adobe dan program aplikasi standar authoring tool professional yang digunakan untuk membuat animasi dan bitmap yang sangat menarik untuk keperluan pembangunan situs web yang interaktif dan dinamis. Flash didesain dengan kemampuan untuk membuat animasi 2 dimensi yang handal dan ringan sehingga flash banyak digunakan untuk membangun dan memberikan efek animasi pada website, $C D$ Interaktif dan yang lainnya. Selain itu aplikasi ini juga dapat digunakan untuk membuat animasi logo, movie, game, pembuatan navigasi pada situs web, tombol animasi, banner, menu interaktif, interaktif form isian, e-card, screen saver dan pembuatan aplikasi-aplikasi web lainnya. Dalam Flash, terdapat teknik-teknik membuat animasi, fasilitas action script, filter, custom easing dan dapat memasukkan video lengkap dengan fasilitas playback FLV. Keunggulan yang dimiliki oleh Flash ini adalah ia mampu diberikan sedikit code pemograman baik yang berjalan sendiri untuk mengatur animasi yang ada di dalamnya atau digunakan untuk berkomunikasi dengan program lain seperti HTML, PHP, dan Database dengan pendekatan XML, dapat dikolaborasikan dengan web, karena mempunyai keunggulan antara lain kecil dalam ukuran file outputnya. Keunggulan yang dimiliki oleh Flash ini adalah ia mampu diberikan sedikit code pemrograman baik yang berjalan sendiri untuk mengatur animasi yang ada di dalamnya atau digunakan untuk berkomunikasi dengan program lain seperti HTML, PHP, dan Database dengan pendekatan XML, dapat dikolaborasikan dengan web, karena mempunyai keunggulan antara lain kecil dalam ukuran file outputnya. Bahasa pemrograman yang digunakan di Adobe Flash adalah Action Script. Action Script 2.0 (ditujukan untuk penggunaan platform desktop) 
dan Action Script 3.0 (ditujukan untuk penggunaan platform mobile) [14].

\section{Metode}

\subsection{Desain Penelitian}

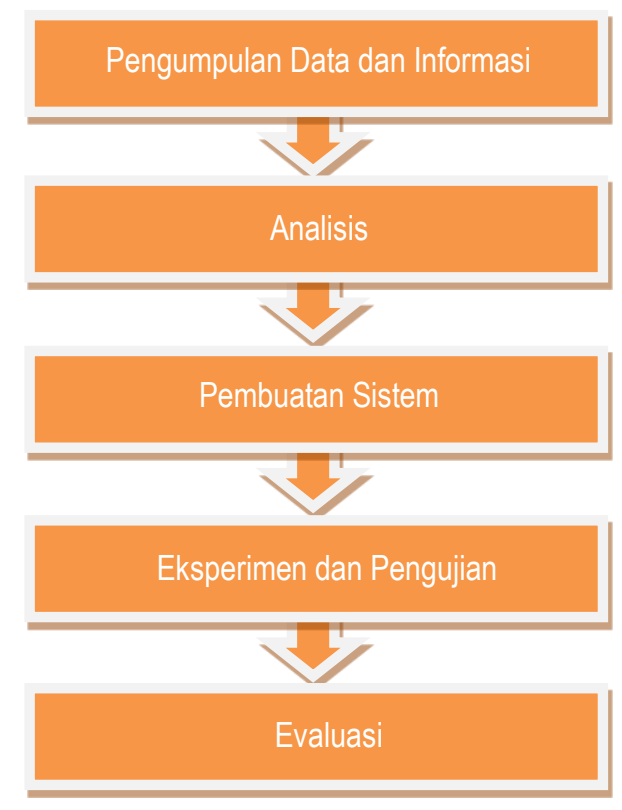

Gambar 1 Tahapan Penelitian

Pada penelitian ini terdapat beberapa tahapan sebagai berikut :

1. Tahap pengumpulan informasi dan data mengenai media pembelajaran yang digunakan.

2. Tahap Analisis

Tahapan analisis ini bertujuan untuk memperoleh media dan metode pembelajaran apa saja yang digunakan para pengajar untuk menyampaikan materi kepada siswa.
3. Tahap Pembuatan Sistem

Pada tahapan pembuatan sistem media pembelajaran interaktif untuk mempermudah dalam menyampaikan materi matematika kepada siswa, dengan pembuatan sistem ini juga diharapkan dapat digunakan oleh siswa dalam meningkatkan minat belajar.

4. Experimen dan Pengujian

Berdasarkan hasil dari sistem media pembelajaran interaktif yang telah dibuat, akan dilakukan uji coba untuk melihat apakah sistem yang dibuat dapat berjalan sesuai dengan yang diinginkan.

5. Evaluasi

Setelah dilakukan pengujian dan experimen terhadap hasil media pembelajaran interaktif yang telah dibuat, maka bisa dilihat perbedaan dari hasil yang dilakukan sebelumnya, apakah dengan pembuatan media pembelajaran interaktif berbasis flash ini dapat membantu meningkatkan minat belajar siswa.

\subsection{Prosedur Penelitian}

Prosedur penelitian merupakan urutan kegiatan yang harus dilalui dalam penelitian yang dilakukakn secara sistematis dengan tujuan untuk mempermudah proses penelitian. Adapun prosedur peneltian yang dilakukan oleh peneliti mulai dengan menganalisis permasalahan yang terdapat pada proses belajar mengajar di MI NW 
Liqaul Amal dan metode pembelajaran apa saja yang digunakan para pengajar untuk menyampaikan materi kepada siswa. Serta media pembelajaran yang diperlukan dalam menyampaikan materi kepada siswa.

\subsection{Sumber Data}

1. Data Primer

Sumber data yang digunakan oleh peneliti adalah hasil dari wawancara dan observasi terhadap proses belajar mengajar yang ada di MI NW Liqaul Amal.

2. Data Sekunder

Sedangkan dalam pengumpulan data sekunder menggunakan buku, jurnal, publikasi dan lain-lain serta data yang sebelumnya pernah dibuat oleh seseorang baik di terbitkan atau tidak.

\subsection{Instrumen Penelitian}

Menurut [15] "Instrumen penelitian adalah suatu alat yang digunakan untuk mengukur nilai variabel yang diteliti dengan tujuan menghasilkan data kuantitatif yang akurat, maka setiap instrumen harus mempunyai skala". Instrumen penelitian yang digunakan dalam penelitian ini adalah dengan mengamati langsung pada obyek penelitian serta dengan cara wawancara.

\subsection{Teknik Pengumpulan Data}

Teknik pengumpulan data dalam penelitian ini menggunakan metode observasi, wawancara dan studi literatur.

1. Oberservasi

Pengumpulan data dan infromasi dengan mengamati langsung ke MI NW Liqaul Amal supaya mendapatkan gambaran yang sesungguhnya mengenai proses belajar mengajar dan metode pembelajaran yang digunakan.

2. Wawancara

Peneliti melakukan wawancara dengan guru MI NW Liqaul Amal untuk mendapatkan data dan informasi yang berkaitan dengan proses belajar mengajar serta media dan metode pembelajaran yang digunakan.

3. Studi Literatur

Pengumpulan data dan informasi dengan membaca buku, jurnal, publikasi dan lainlain serta data yang sebelumnya pernah dibuat oleh seseorang baik di terbitkan atau tidak yang dapat digunakan sebagai acuan dalam melaksanakan penelitian.

\subsection{Teknik Analisis Data}

1. Analisis Permasalahan

Melakukan analisis terhadap permasalahan atau kendala yang dihadapi terkait dengan proses belajar mengajar dan metode pembelajaran yang digunakan, serta 
memberikan solusi terhadap masalah yang ditemukan.

2. Analisis Kebutuhan

Peneliti menganalisis kebutuhan media yang dibutuhkan dalam proses belajar mengajar.

\subsection{Lokasi Penelitian}

Lokasi dalam penelitian ini dilakukan di MI NW Liqaul Amal desa Sepit kecamatan Keruak kabupaten Lombok Timur.

\section{Hasil dan Pembahasan}

Media pembelajaran interaktif Matematika ini diterapkan di MI NW Liqaul Amal desa Sepit kecamatan Keruak sebagai media belajar mengajar yang lebih menarik dan menyenangkan. Dengan adanya media pembelajaran interaktif ini, dapat menarik minat belajar dan menambah motivasi anak selama belajar sehingga didapatkan hasil pembelajaran yang maksimal. Selain itu, dapat membantu guru dalam menyampaikan materi kepada siswa dengan mudah melalui media pembelajaran interaktif ini. Agar bisa menjalankan media pembelajaran interaktif ini, guru hanya perlu menggunakan PC atau laptop. Langkah-langkah untuk membukanya adalah sebagai berikut :

0. Klik dua kali pada icon aplikasi Adobe Flash Media Pembelajaran Interaktif.

1. Kemudian akan langsung menuju interface halaman utama aplikasi.
Adapun hasil dari uji coba aplikasi media pembelajaran interaktif ini adalah sebagai berikut:

1. Halaman Intro

Tampilan menu halaman intro setelah dijalankan, pada tampilan halaman ini terdapat sountrack yang mengucapkan "Media Pembelajaran Matematika". Adapun tampilan gambarnya dapat dilihat pada gambar di bawah ini.

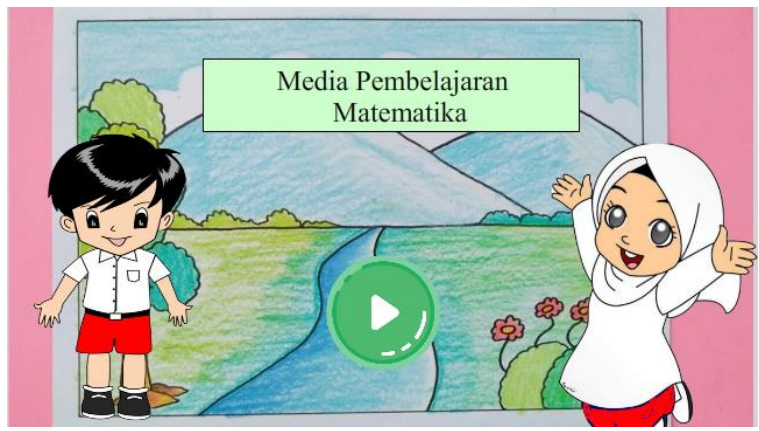

Gambar 2 Halaman Intro

\section{Menu Utama}

Tampilan menu utama setelah dijalankan, dimana halaman ini menampilkan keseluruhan menu yaitu menu kelas 1 , video, video materi, kuis dan Ki\&Kd.

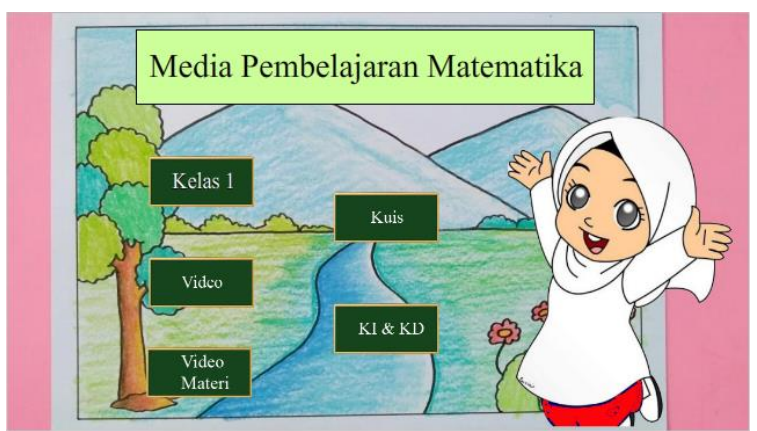

Gambar 3. Media Pembelajaran Matematika 


\section{Kelas Satu}

Tampilan menu kelas satu setelah dijalankan, dimana halaman kelas satu ini akan menampilkan pembelajaran tentang pengurangan.

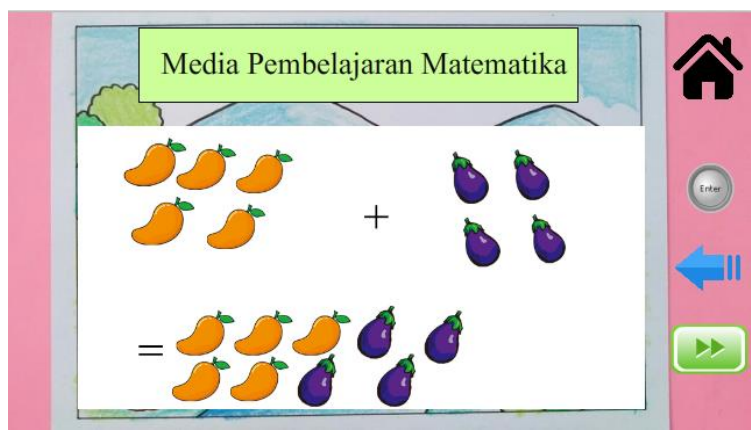

Gambar 4. Kelas Satu

\section{Video Pembelajaran}

Tampilan menu video pembelajaran setelah dijalankan, dimana menu halaman ini menampilkan video pembelajaran yang bertujuan agar anak-anak tidak bosan ketika belajar. Adapun tampilan gambarnya dapat dilihat pada gambar di bawah ini.

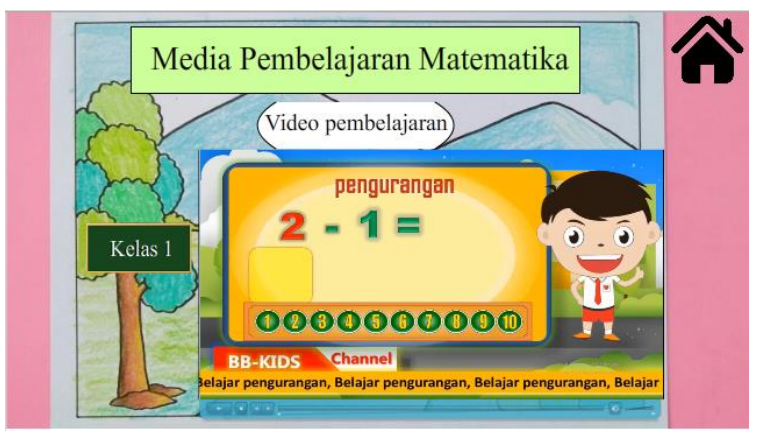

Gambar 5. Video Pembelajaran

\section{Menu Video Materi}

Menu video materi ini akan menampilkan video pembelajaran kelas 1. Dan adapaun tampilan gambarnya dapat dilihat pada gambar di bawah ini.

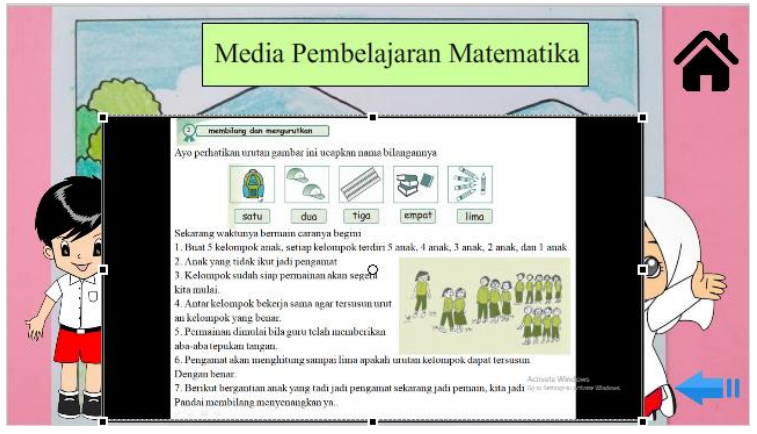

Gambar 6. Video Materi

\section{Menu KI \& KD}

Menu ini berisi tentang kompetensi inti dan kompetensi dasar yang sudah menjadi ketentuan dari pihak madrasah. Dan adapaun tampilan gambarnya dapat dilihat pada gambar di bawah ini.

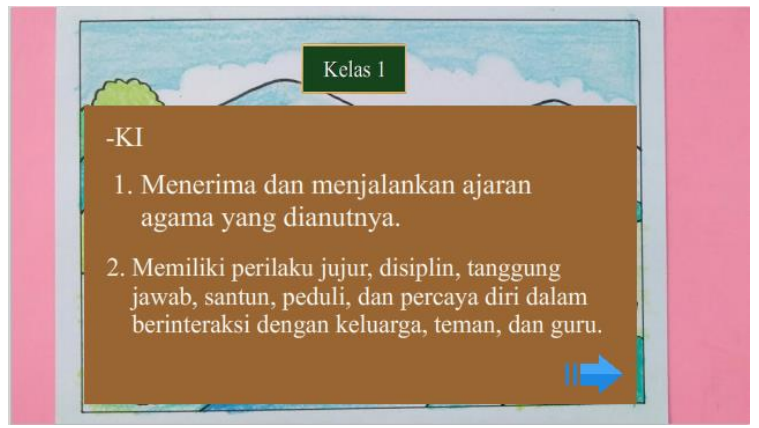

Gambar 7. KI \& KD

\section{Kuis}

Tampilan menu kuis setelah dijalankan, dimana menu kuis ini menampilkan lima soal matematika yang dimana setiap soal memiliki point 20. 


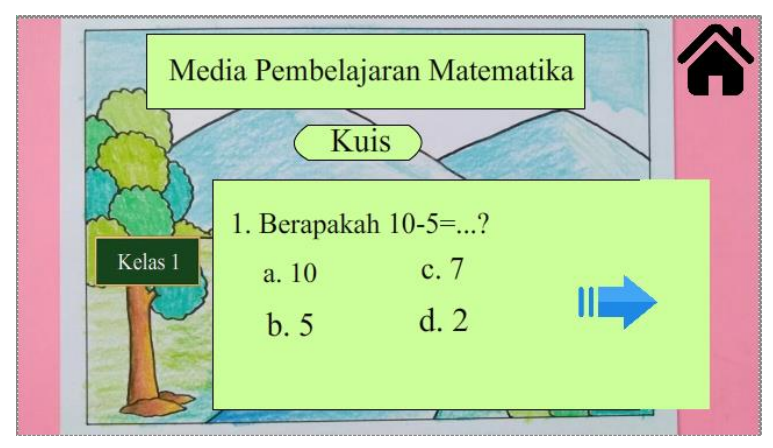

Gambar 8. Kuis

\section{Kesimpulan}

Pembuatan media pembelajaran interaktif berbasis adobe flash pada media pembelajaran matematika untuk kelas I MI NW Liqaul Amal agar dapat mempermudah guru dan siswa dalam proses belajar mengajar. Dengan adanya media pembelajaran interaktif matematika ini dapat membuat siswa menjadi termotivasi dalam kegiatan belajar mengajar serta dapat meningkatkan minat dan ketertarikan siswa untuk belajar khususnya pada mata pelajaran matematika. Dikarenakan media interaktif ini menggabungkan suara, gambar dan video yang dikemas agar dapat menarik minat belajar siswa dan memberikan motivasi baru dalam proses belajar mengajar.

\section{Daftar Pustaka}

[1] Bahtiar, H., Wasil, M., \& Harianto, B. (2019). Digitalisasi Karya TGKH. Muhammad Zainuddin Abdul Madjid berbasis mobile sebagai media pembelajaran interaktif untuk pelestarian peninggalan pendiri Nahdlatul Wathan. Infotek J. Inform. dan
Teknol, 88(5), 427-434.

[2] Sudianto, A., \& Samsu, L. M. (2019). Penerapan Media Pembelajaran Interaktif Pelajaran Bahasa Indonesia Berbasis Android Untuk Kelas VII Madrasah Tsanawiyah Nahdlatul Wathan Ketangga Sebagai Upaya Untuk Peningkatkan Minat Belajar Siswa. Infotek: Jurnal Informatika dan Teknologi, 2(2), 53-60.

[3] Wirasasmita, R. H., \& Putra, Y. K. (2018). Pengembangan media pembelajaran video tutorial interaktif menggunakan aplikasi camtasia studio dan macromedia flash. EDUMATIC: Jurnal Pendidikan Informatika, 1(2), 35-43.

[4] H. Bahtiar, "Sistem Informasi Wisata dan Budaya Pulau Lombok dengan Multimedia Intraktif Untuk Meningkatkan Kunjungan Wisata Hariman," vol. 1, no. 1, pp. 1-10, 2018.

[5] Fathurrahman, F., Putra, Y. K., \& Sadali, M. (2020). Media Pembelajaran Interaktif Pengenalan Huruf Berbasis Flash Pada Siswa Pendidikan Anak Usia Dini (PAUD)(Studi Kasus: Kelompok Belajar Tarbiyatul Ummah Tanak Kaken Sakra Barat). Infotek: Jurnal Informatika dan Teknologi, 3(2), 211-219.

[6] I. Diah, S. Nita, D. T. Informatika, F. Teknik, and U. P. Madiun, "Media Pembelajaran Berbasis Multimedia Interaktif untuk Meningkatkan Pemahaman Konsep Mahasiswa," vol. 1, no. 2, pp. 68-75, 2018.

[7] G. Mussardo, "Definisi Multimedia dan Unsur Multimedia," Stat. F. Theor, vol. 53, no. 9, pp. 1689-1699, 2019, doi: 10.1017/CBO9781107415324.004.

[8] Arsyad, A. (2011). Media pembelajaran. Jakarta: PT. Raja Grafindo Persada.

[9] Nurdyansyah, N., \& Fahyuni, E. F. (2016). Inovasi model pembelajaran sesuai kurikulum 2013.

[10] Sudjana, N., \& Rivai, A. (2011). Media Pengajaran (Penggunaan \& Pembuatannya). Sinar Baru Aglesindo, Bandung, 2011. 
[11] A. and Munir, "Media Pembelajaran Interaktif," vol. 13, no. 128, p. 234, 2011.

[12] Daryanto, Media Pembelajaran. Bandung: PT. S a r a $n$ a Tutorial Nurani Sejahtera, 2011.

[13] Sekti, T. (2019). Pengembangan Media Pembelajaran Interaktif Berbasis Adobe Flash Pada Muatan SBdP Materi Mozaik Siswa Kelas IV SDN Purwosari 01 Semarang (Doctoral dissertation, Universitas Negeri Semarang).

[14] Mustaqim, I., \& Prianto, E. (2015). Modul Pelatihan Media Pembelajaran Adobe Flash. Fak. Tek. Univ. Negeri Yogyakarta, no. April, 1-45.

[15] Sugiyono, P. (2011). Metodologi penelitian kuantitatif kualitatif dan R\&D. Alpabeta, Bandung.

[16] A. Sudianto and H. Ahmadi, "Rancang Bangun Sistem Informasi Penjualan Sparepart Motor Pada Bengkel Vinensi Motor Berbasis Web Guna Meningkatkan Penjualan dan Promosi Produk Pendahuluan Vinensi sepeda motor motor," Infotek J. Inform. dan Teknol., vol. 3, no. 2, pp. 32-39, 2020. 